\title{
Correlations Between Symptoms, Nasal Endoscopy Computed Tomography and Surgical Findings in Patients with Chronic Rhinosinusitis
}

\author{
Pokharel M, ${ }^{1}$ Karki S, ${ }^{2}$ Shrestha BL, ${ }^{1}$ Shrestha $I,{ }^{1}$ Amatya RCM ${ }^{1}$
}

${ }^{1}$ Department of ENT and Head and Neck Surgery

${ }^{2}$ Department of Radiodiagnosis and Imaging

Dhulikhel Hospital- Kathmandu University Hospital Kathmandu University School of medical Science

Dhulikhel, Kavre, Nepal

\section{Corresponding author}

Monika Pokharel

Department of ENT and Head and Neck Surgery

Dhulikhel Hospital- Kathmandu University Hospital Kathmandu University School of medical Science

Dhulikhel, Kavre, Nepal

Email: monikapokharel@hotmail.com

Citation

Pokharel M, Karki S, Shrestha BL, Shrestha I, Amatya RCM. Correlations Between Symptoms, Nasal

Endoscopy, Computed Tomography and Surgical Findings in Patients with Chronic Rhinosinusitis. Kathmandu Univ Med J 2013;43(3):201-205.

\begin{abstract}
Background

Although Chronic rhinosinusitis (CRS) is increasing in prevalence and incidence, its diagnosis and treatment still pose a challenge. The Task Force on rhinosinusitis (TFR) advocates the use of symptom based criteria. However, many otorhinolaryngologists depend on diagnostic nasal endoscopy and computed tomography(CT) of paranasal sinuses for diagnosis of CRS. Computed tomography has been extensively relied upon in confirming the presence of CRS, in assessing severity of disease, surgical planning and management decisions. Despite its widespread use, several studies have failed to correlate findings on CT with symptom severity.
\end{abstract}

\section{Objective}

To determine the correlations between symptoms described at presentation, radiological findings, endoscopy and extensiveness of surgery.

\section{Methods}

Longitudinal, prospective, analytical study conducted from August 2011 to August 2012 among 87 patients diagnosed as CRS according to the TFR criteria. Symptom, endoscopic, radiological and surgical scoring was done by using Lund and Mackay staging system. Pearson correlation coefficients between scores for symptoms, endoscopy, sinus CT and surgery was determined.

\section{Results}

When overall symptom score was correlated with radiological score and endoscopy score, it was found to be statistically significant $(p=<0.01)$. However, no significant relationship was found between Lund and Mackay symptom and surgery score.

\section{Conclusion}

The symptom criteria used by TFR for CRS diagnosis are not very specific for sinus disease. A detail assessment of the subjective and objective criteria (CT and endoscopy) is necessary for tailoring surgical plan but should not be relied upon for determining the extensiveness of surgical intervention.

\section{KEY WORDS}

Chronic rhinosinusitis, lund and mackay staging system, task force on rhinosinusitis

\section{INTRODUCTION}

Chronic rhinosinusitis(CRS) is a very common disease that results in significant impact on economy and quality of life which is comparable or even worse to other chronic debilitating diseases such as diabetes and congestive heart failure. ${ }^{1}$ Although frequently encountered, its diagnosis and treatment still pose a challenge. ${ }^{2}$ Incorrectly diagnosing CRS can result in delaying correct treatment and risk side effects from improperly selected therapy.
In 1997, the TFR set forth diagnostic guidelines for diagnosis of CRS. A key feature of the TFR definitions of rhinosinusitis is its emphasis on symptoms rather than objective findings for establishing a diagnosis. The intent of using a symptom-based criteria was to provide clinicians of all specialities a means of diagnosing rhinosinusitis without requiring expensive modalities such as CT or nasal endoscopy. ${ }^{3}$ However, by general clinical practice, many 
otorhinolaryngologists rely on paranasal sinus computed tomography and diagnostic nasal endoscopy to confirm and assess severity of disease, and aid in management decisions.

Computed tomography scanning of the paranasal sinuses has become the gold standard in the evaluation and surgical planning for CRS and is thought to be an integral component in the diagnosis of CRS. ${ }^{4}$ However, despite its widespread use, the sensitivity, specificity, and diagnostic accuracy of the paranasal sinus CT scanning for CRS have not been rigorously assessed. ${ }^{5}$

The purpose of this study is to determine the correlations between the Lund and Mackay symptom score, radiological score, endoscopy score and surgery score.

\section{METHODS}

This was a longitudinal prospective, analytical study conducted from August 2011 to August 2012 in the ENT and head and neck surgery department at the Kathmandu University Dhulikhel Hospital, Kavre.

Eighty seven patients diagnosed as CRS by the widely accepted definition developed by the Rhinosinusitis Task Force of the American Academy of Otolaryngologyhead and neck surgery and reported by Lanza et.al were included in the study. 3,6 Patients with malignancy of paranasal sinuses, acute rhinosinusitis, pregnancy, immunocompromised state, cystic fibrosis and age less than 17 years were excluded from the study. A detailed history was taken and proforma was filled up. Written informed consent was taken and approval was obtained from institutional review committee Kathmandu University School of Medical Sciences. Patients were asked about the symptoms they were suffering from and scoring was done by Lund and Mackay staging system by using Visual Analogue method. ${ }^{7}$

Diagnostic nasal endoscopy was performed after packing the nasal cavity with $4 \%$ Xylocaine for 15 minutes. Nasal decongestant was also used prior to endoscopy since it was difficult to negotiate the endoscope because of congested turbinates and mucosa. The endoscopy was performed by using a $4 \mathrm{~mm} 0$ degree and 45 degree endoscope by the same surgeon for all the patients in order to avoid interobserver bias. The presence or absence of nasal polyps, oedema and discharge was noted and an endoscopic score was derived according to Lund-Mackay scoring system. The extent of polyp was graded on the basis of 3 point classification system (Score 0-No polyp; Score 1-restricted to middle meatus; Score 2-below middle meatus; Score 3-massive polyposis as shown in fig 1) and a score was assigned. Score was also derived for oedema and discharge as follows-discharge (0-none;1-clear and thin; 2-thick and purulent), oedema (0-absent;1-mild;2-severe) as shown in fig 2 . The scores for each sided nasal cavity was summed up so that the range of score was 0-4 for each side and the total score was 20. For this study, Score 1 or above was considered abnormal.

Using the parameters $-120 \mathrm{kV}, 500 \mathrm{~mA}$, a complete coronal CT scan was taken with $3 \mathrm{~mm}$ slices concentrating on the osteomeatal complex and paranasal sinuses.The analysis of the CT scan and the Lund Mackay Radiological scoring was performed by a single radiologist blinded to patient's symptoms and endoscopy findings over the whole period of study in order to avoid interobserver bias. A numerical score was assigned for the maxillary, anterior ethmoid, posterior ethmoid, sphenoid and frontal sinuses and the osteomeatal complex on the following scale:0-no opacification,1- partial opacification, 2- complete opacification (fig 3). However, osteomeatal unit was scored as 0-no opacification, 2-total

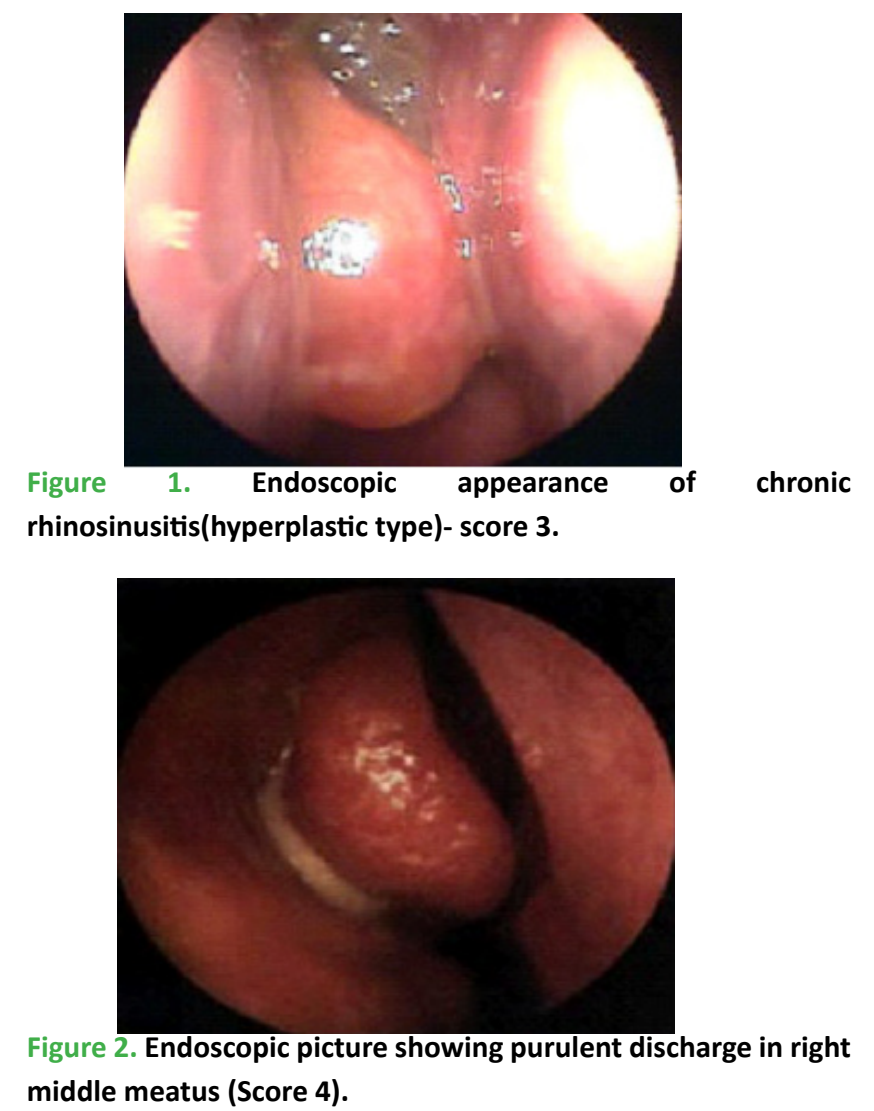
middle meatus (Score 4).

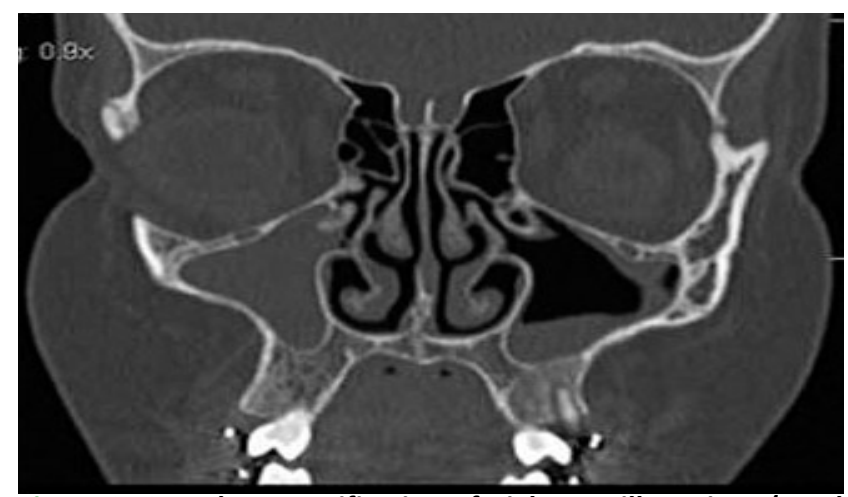

Figure 3. Complete opacification of Right maxillary sinus (Lund and Mackay Radiological Score 2),partial opacification of Left maxillary sinus(Lund and Mackay Radiological Score 1) with no opacification in bilateral ethmoid sinuses (Lund and Mackay Radiological Score 0). 
opacification. Again, each side was graded separately and the scores from each side were then added to determine the overall radiological score which ranged from 0 to 24 . The score of 1 or above was considered abnormal for this study. Patient was taken up for surgery after obtaining a proper written informed consent. Again numerical score was derived for each side separately depending upon the extent of surgery performed on the uncinate process, anterior ethmoids, posterior ethmoids, middle meatus, frontal recess, sphenoids, middle turbinate as follows 0-no procedure carried out, 1-surgery carried out. The maximum score was 0-7 for each side making a total of 14 for both.

Collected data were entered and analyzed using SPSS software 16.0. Both descriptive and inferential statistics were measured. Pearson's $r$ correlation analysis between total Lund and Mackay Symptom, Radiological, Surgery and Endoscopic scores was determined.

\section{RESULTS}

Eighty seven patients were evaluated and underwent CT scan of the osteomeatal unit and the paranasal sinuses. Thirty two (36.8\%) patients were male and 55(63.2\%) were female.(Table 1) The age of patients ranged from 17 to 55 years (mean age 31.87 years). Table 2 shows the number and percentage of patients having a particular symptom according to visual analogue scale (VAS). The mean of Lund and Mackay scores are shown in table 3. We studied the correlation between the Lund and Mackay overall Symptom, Radiological, Endoscopy and Surgical score using Pearson's r correlation analysis. For Pearson's correlation coefficient $p$ values $<0.01$ was set to achieve statistical significance. High degree of correlation was seen between Lund and Mackay overall symptom score and extent of disease on CT and endoscopy score. However, Lund and Mackay symptom score correlated with surgery score failed to achieve statistical significance (table 4).

Table 1. Demographic characteristics $(n=87)$.

\begin{tabular}{|c|c|}
\hline Variables & Frequency (\%) \\
\hline \multicolumn{2}{|c|}{ Sex } \\
\hline Male & $32(36.8 \%)$ \\
\hline Female & $55(63.2 \%)$ \\
\hline \multicolumn{2}{|c|}{ Age } \\
\hline$<20$ years & 11 (12.64\%) \\
\hline $21-24$ years & $20(22.98 \%)$ \\
\hline $25-29$ years & $7(8.04 \%)$ \\
\hline $30-34$ years & $16(18.39 \%)$ \\
\hline $35-39$ years & $6(6.89 \%)$ \\
\hline $40-44$ years & $18(20.68 \%)$ \\
\hline $45-49$ years & $6(6.89 \%)$ \\
\hline$>50$ years & $3(3.44 \%)$ \\
\hline
\end{tabular}

Table 2. Number and percentage of patients with Major and Minor rhinosinusitis symptoms as listed by the American Task force on Rhinosinusitis ( $n=87$ ).

\begin{tabular}{|c|c|c|}
\hline \multirow{6}{*}{ 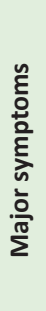 } & Symptoms & Frequency (\%) \\
\hline & Nasal obstruction & $74(85.1 \%)$ \\
\hline & Post nasal discharge & $24(27.6 \%)$ \\
\hline & Nasal discharge & $22(25.3 \%)$ \\
\hline & Facial pain or pressure & $2(2.3 \%)$ \\
\hline & Hyposmia/anosmia & $7(8 \%)$ \\
\hline \multirow{8}{*}{ 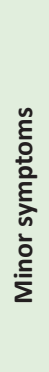 } & Nasal congestion & $0(0 \%)$ \\
\hline & Headache & $70(80.5 \%)$ \\
\hline & Halitosis & $5(5.7 \%)$ \\
\hline & Fever & $0(0 \%)$ \\
\hline & Fatigue & $0(0 \%)$ \\
\hline & Dental pain & $0(0 \%)$ \\
\hline & Cough & $0(0 \%)$ \\
\hline & Ear pain or fullness & $0(0 \%)$ \\
\hline
\end{tabular}

Table 3. Mean of Lund and Mackay scores.

\begin{tabular}{|llll|}
$\begin{array}{l}\text { Lund and Mackay } \\
\text { scores }\end{array}$ & $\mathbf{N}$ & Mean & SD \\
\hline Radiological score & 87 & 11.30 & 5.241 \\
\hline Surgery Score & 87 & 9.86 & 2.426 \\
\hline Symptom Score & 87 & 30.80 & 9.494 \\
\hline Endoscopy Score & 87 & 6.32 & 3.248 \\
\hline
\end{tabular}

Table 4. Correlations between Lund and Mackay Radiological, surgery, symptom and Endoscopy scores.

\begin{tabular}{|c|c|c|c|c|c|}
\hline & & $\begin{array}{l}\text { Radiologi- } \\
\text { cal score }\end{array}$ & $\begin{array}{l}\text { Surgery } \\
\text { Score }\end{array}$ & $\begin{array}{l}\text { Symp- } \\
\text { tom } \\
\text { Score }\end{array}$ & $\begin{array}{l}\text { Endos- } \\
\text { copy } \\
\text { Score }\end{array}$ \\
\hline \multirow[t]{3}{*}{$\begin{array}{l}\text { Radiologi- } \\
\text { cal score }\end{array}$} & $\begin{array}{l}\text { Pearson } \\
\text { Correla- } \\
\text { tion }\end{array}$ & 1 & $0.462 * *$ & $0.371 * *$ & $0.556^{* *}$ \\
\hline & $P$ value & & 0.000 & 0.000 & 0.000 \\
\hline & $\mathrm{N}$ & 87 & 87 & 87 & 87 \\
\hline \multirow[t]{3}{*}{$\begin{array}{l}\text { Surgery } \\
\text { Score }\end{array}$} & $\begin{array}{l}\text { Pearson } \\
\text { Correla- } \\
\text { tion }\end{array}$ & $0.462 * *$ & 1 & 0.153 & $0.347^{* *}$ \\
\hline & $P$ value & 0.000 & & 0.158 & 0.001 \\
\hline & $\mathrm{N}$ & 87 & 87 & 87 & 87 \\
\hline \multirow[t]{3}{*}{$\begin{array}{l}\text { Symptom } \\
\text { Score }\end{array}$} & $\begin{array}{l}\text { Pearson } \\
\text { Correla- } \\
\text { tion }\end{array}$ & $0.371^{* *}$ & 0.153 & 1 & $0.393^{* *}$ \\
\hline & $P$ value & 0.000 & 0.158 & & 0.000 \\
\hline & $\mathrm{N}$ & 87 & 87 & 87 & 87 \\
\hline \multirow[t]{3}{*}{$\begin{array}{l}\text { Endosco- } \\
\text { py Score }\end{array}$} & $\begin{array}{l}\text { Pearson } \\
\text { Correla- } \\
\text { tion }\end{array}$ & $0.556 * *$ & $0.347^{* *}$ & $0.393 * *$ & 1 \\
\hline & $P$ value & 0.000 & 0.001 & 0.000 & \\
\hline & $\mathrm{N}$ & 87 & 87 & 87 & 87 \\
\hline
\end{tabular}




\section{DISCUSSION}

Chronic rhinosinusitis is a very pervasive medical problem and can be challenging to treat. It causes significant physical symptoms, negatively affects quality of life, and can substantially impair daily functioning. Despite its prevalence and impact, definitive clinical diagnostic criteria for CRS remain controversial and in flux. ${ }^{8}$ The fact that diagnosis relies on a series of subjective symptoms with few objective criteria only contributes to the problem. ${ }^{9}$

It has been recently recommended that either a CT scan or endoscopic evaluation of nose (preferably with photo or video documentation) should be a part of any prospective clinical trial, as it provides the majority of objective data used to diagnose CRS. ${ }^{10-15}$

In an effort to standardize the CT scan evaluation, there have been a number of attempts to establish staging systems to assess the severity and to investigate another means for objective identification and quantification of CRS. Other useful staging systems have been revised, but the TFR recommends using Lund system for staging in clinical research. This recommendation is based on ease of use and accurate reproducibility of scores.

In the present study, among 87 patients, 32 (36.8\%) patients were male and 55(63.2\%) were female, which is similar to previously reported gender distributions in some of the other studies. ${ }^{16,17}$ The age of patients in our study ranged from 17 to 55 years (mean age 31.87 years), which is similar to study performed by Hwang et al who reported mean age of patients as 47.4 years. ${ }^{17}$ Our findings are in contrast to study performed by Kenny TJ et al who have included patients belonging to pediatric age group in their study. ${ }^{16}$

Many researchers have attempted to correlate the symptom severity of CRS with the extent of disease on sinus CT scan, however, the relationship between the two remains controversial. ${ }^{18}$ In the current study, when the symptoms described by the patient was correlated with disease severity as observed on CT scan, it was found to be statistically significant. This means that patients with more severe symptom scores are more likely to have CT imaging evidence supporting the diagnosis of rhinosinusitis. This could be explained because most of the patients included in our study group belonged to the skewed population who presented very late and did not respond to all forms of medical therapy for rhinosinusitis for prolonged periods of time. Thus they had severe mucosal changes which was correctly picked up by the CT scan and revealed by nasal endoscopy. This observation is similar to the study performed by Kenny et al. ${ }^{16}$ However, some other authors have observed no significant correlation between severity of symptoms and CT scores. 5,13,14,17,18

There have been several studies in the past which have found mixed association between sinus CT scan findings and nasal endoscopy. Studies evaluating the accuracy of nasal endoscopy in predicting sinus CT scan findings in presurgical CRS patients have found mixed results. Stankiewicz et al reported that nasal endoscopy had a sensitivity of $46 \%$, specificity $86 \%$, positive predictive value $74 \%$, and negative predictive value of $64 \%$ and showed that there was poor correlation between nasal endoscopy and sinus CT. ${ }^{19}$ However, in the present study, we observed statistically significant correlation between radiological score and endoscopy score. This is a finding supported by other studies. ${ }^{15,20,21}$

While many published articles exist on the correlations between Lund and Mackay symptom, endoscopy and radiological scores, to our knowledge there has been no research till date comparing the correlations between symptoms score with surgical findings. This has important implications in properly assessing the weight of subjective symptom description and objective radiological, endoscopic and surgery scores. Our data demonstrate that eventhough the symptom score correlates well with radiological and endoscopy score, it shows poor correlation with surgery score. This could be because the symptom criteria used by TFR for CRS diagnosis are not specific for sinus disease and requires further refinement. This increases the risk of misdiagnosis and is the subject of ongoing clinical research. Moreover, studies analyzing CT scans of asymptomatic patients have shown rates of incidental opacification in $27 \%$ to $42 \% .{ }^{13,22-26}$ The same could have been true in our patients, whose positive $\mathrm{CT}$ findings could have been incidental. We also admit that most of the otorhinolaryngologists including us have the tendency to rely to some extent on sinus CT findings for surgical planning. However, since the findings were incidental, when the patient was being operated, there were not as much mucosal abnormalities as expected by looking at the CT. So, the surgeon could have limited the surgical procedure. This could be the reason why, the symptom score did not correlate with the surgery score. In light of these findings, we suggest that a careful assessment of the subjective and objective (CT and endoscopy) criteria is necessary for surgical preparation but not for determining the need for surgical intervention.

Some points regarding the use of Lund and Mackay CT scoring system for CRS severity assessment merit comment. Although, it addresses the mucosal thickening and the extent of sinus opacification, it does not consider important anatomical factors like congenital variations in paranasal sinuses. Moreover, determination of Lund Mackay symptom score on the basis of patient reported severity of symptoms by using Visual analogue scale seems to be unreliable since it is a subjective method of symptom assessment .The limitation of our study is the small sample size which might be the reason why our observations were different as compared to other studies which are based on large number of patients. The literature focusing on correlations between the Lund Mackay scores, specially the symptom and the surgery score is very scarce, and therefore further future research on this area is warranted. 


\section{CONCLUSION}

When the Lund and Mackay overall symptom score was correlated with the radiological and endoscopy score, it was found to be statistically significant. However, Lund and Mackay symptom score correlated with surgery score failed to achieve statistical significance. The Task Force on Rhinosinusitis symptom criteria for Chronic Rhinosinusitis diagnosis are not specific to sinus disease. This lack of specificity increases the chances of misdiagnosis and is a subject of ongoing clinical research. A vigilant assessment of the subjective and objective clinical variables (CT

\section{REFERENCES}

1. Glicklich RE, Metson R. The health impact of chronic sinusitis in patients seeking otolaryngologic care. Otolaryngo and Head and Neck Surgery. 1995;113:104-9.

2. Kaliner MA, Osguthorpe JD, Fireman P, Anon J, Georgitis J, Davis ML et al. Sinusitis: bench to bedside. Current findings, future directions. Otolaryngol Head Neck Surg. 1997 Jun;116(6 Pt 2):S1-20.

3. Lanza DC, Kennedy DW. Adult rhinosinusitis defined. Otolaryngol Head Neck Surg. 1997;117:s1-7.

4. Zinreich J. Rhinosinusitis: radiologic diagnosis. Otolaryngol Head Neck Surg 1997;117:S27-S34.

5. Bhattacharyya N., Fried M. The accuracy of computed tomography in the diagnosis of Chronic Rhinosinusitis. Laryngoscope 2003; 113:125129.

6. Report of the Rhinosinusitis Task Force Committee Meeting. Otolaryngology and Head and Neck Surgery.1997;117:S1-68.

7. Lund VJ, Mackay IS. Staging in rhinosinusitis. Rhinology. 1993 Dec;31(4):183-4.

8. Bhattacharyya N, Lee LN. Evaluating the diagnosis of Chronic rhinosinusitis based on clinical guidelines and endoscopy. Otolaryngol Head Neck Surg. 2010 Jul;143(1):147-51.

9. Arango P, Kountakis SE. Significance of Computed Tomography Pathology in Chronic Rhinosinusitis. Laryngoscope. 2001;111:17791782.

10. Benninger MS, Ferguson BJ, Hadley JA, Hamilos DJ, Jacobs $M$, Kennedy DW et al. Adult chronic rhinosinusitis : Definitions, diagnosis, epidemiology and pathophysiology. Otolaryngol Head Neck Surg. 2003;129:1-32.

11. Zinreich SJ. Rhinosinusitis: radiologic diagnosis. Otolaryngol Head Neck Surg.1997;117(part 2):27-34.

12. Lund VJ, Kennedy DW. Staging for rhinosinusitis. Otolaryngol Head Neck Surg. 1997;117(part 2):35-40.

13. Stewart MG, Sicard MW, Piccirillo JF, Diaz-Marchan PJ. Severity staging in chronic sinusitis: are CT scan findings related to patient symptoms? Am J Rhinol. 1999;13:161-167.

14. Bhattacharyya T, Piccirillo J, Wippold J. Relationship between patient-based description of sinusitis and paranasal sinus computed tomographic findings. Arch Otolaryngol Head Neck Surg. 1997;123:1189-92. and endoscopy) by the clinician is required for surgical preparation but not for determining the extensiveness of surgical intervention. We hope that more research which determine correlations between subjective symptom criteria and objective surgical findings will be undertaken in future.

\section{ACKNOWLEDGEMENT}

The authors are grateful to Mr. Seshananda Sanjel and Mr. Kedar Manandhar from Department of Community Medicine for helping in statistical analysis.

15. Rosbe KW, Jones KR. Usefulness of patient symptoms and nasal endoscopy in the diagnosis of chronic rhinosinusitis. Am J Rhinol. 1998;12:167-171.

16. Kenny TJ, Duncavage J, Bracikowski J, Yildirim A, Murray JJ. Prospective analysis of sinus symptoms and correlation with paranasal computed tomography scan. Otolaryngol Head Neck Surg 2001;125:40-3.

17. Hwang PH, Irwin SB, Griest SE, Caro JE, Nesbit GM. Radiologic correlates of symptom-based diagnostic criteria for chronic rhinosinusitis. Otolaryngol Head Neck Surg. 2003 Apr; 128(4):489-96.

18. Hopkins C, Browne JP, Slack R, Lund V, Brown P. The Lund-Mackay Staging system for chronic rhinosinusitis: How is it used and what does it predict? Otolaryngol Head Neck Surg. 2007;137:555-561.

19. Stankiewicz JA, Chow JM. A diagnostic dilemma for chronic rhinosinusitis: definition accuracy and validity. Am J Rhinol 2002;16:199-202.

20. Casiano RR. Correlation of clinical examination with computed tomography in paranasal sinus disease. Am J Rhinol. 1997;11:193-196

21. Nass RL,Holliday RA, Reede DL. Diagnosis of surgical sinusitis using nasal endoscopy and computerized tomography. Laryngoscope 1989;99:1158-1160.

22. Glasier CM, Ascher DP, Williams KD. Incidental paranasal sinus abnormalities on CT of children: clinical correlation. AJNR Am J Neuroradiol. 1986;7:861-864.

23. Diament MJ, Senac MO Jr, Gilsanz V, Baker S, Gillespie T, Larsson S. Prevalence of incidental paranasal sinuses opacification in pediatric patients: a CT study. J Comput Assist Tomogr. 1987 MayJun;11(3):426-31.

24. Havas TE, Motbey JA, Gullane PJ. Prevalence of incidental abnormalities on computed tomographic scans of the paranasal sinuses. Arch Otolaryngol Head Neck Surg. 1988;114:856-859.

25. Flinn J, Chapman ME, Wightman AJ, Maran AG. A prospective analysis of incidental paranasal sinus abnormalities on CT head scans. Clin Otolaryngol Allied Sci. 1994 Aug;19(4):287-9.

26. Bolger WE, Butzin CA, Parsons DS. Paranasal sinus bony anatomic variations and mucosal abnormalities. Laryngoscope. 1991;101:5664. 